\title{
Pioneering studies on the mechanisms of neuronal morphogenesis
}

\author{
Timothy M. Gomez \\ Department of Neuroscience, University of Wisconsin, Madison, WI 53706
}

Growth cones of developing neurons use environmental cues to guide their nascent axons and dendrites to the proper target locations. A fundamental principle explaining how axons are guided is through the coordination of growth cone protrusion and adhesion by intracellular signaling. Neuronal growth cones, like any motile cell, physically adhere to an insoluble cellular or extracellular matrix substratum, which allows them to generate the traction forces necessary to sustain forward movement. Adhesion occurs through a number of distinct cell surface receptors that link to the cytoskeleton. Receptors often also activate intracellular signaling cascades that positively or negatively regulate growth cone motility. Receptor generated signals can occur downstream of both substratum-associated and soluble factors. Finally, accumulating evidence suggests that receptor-generated biochemical changes within growth cones feedback to modulate cell-substratum adhesion (Fig 1). Studies by Paul Letourneau and his colleagues over the last 3 decades have contributed significantly to our understanding of the cellular and molecular basis for axon outgrowth and guidance.

\section{Adhesion and receptor-mediated signaling guide axon outgrowth}

Pioneering work by Paul Letourneau while a graduate student with Norman Wessells at Stanford University and then as an independent investigator there demonstrated that adhesion of growth cones to non-biological substrata was sufficient to promote and guide axon outgrowth (Letourneau, 1975; Letourneau, 1979; Letourneau, 1979). Using patterned substrata of defined adhesiveness, Paul was the first to show that growth cones could be directed in vitro by differences in adhesion. This fundamental observation and his experimental paradigm profoundly influenced the emerging field of axon guidance. These early experiments implied that axons may be targeted in vivo by adhesive interactions with extracellular ligands. A number of different cell recognition molecules on the surface of growth cones are known to have adhesive properties (Rutishauser, 1985; Lagenaur and Lemmon, 1987; Schmidt et al., 1995), which function to stabilize leading protrusions. While it is still uncertain the relative contributions of adhesive contacts versus biochemical signaling in the control of axon pathfinding in vivo, it is likely that differential cell adhesion is an important controlling factor (Caudy and Bentley, 1986; Caudy and Bentley, 1986; O'Connor et al., 1990). It is also important to note that receptors that promote cell adhesion also activate biochemical signals, some of which likely feedback to influence adhesion. Another significant contribution from Paul's early work was his use of micro-patterned substrata to experimentally control axon guidance and provide scenarios to test the relative contributions of adhesion versus biochemical signaling. Since growth cones are believed to navigate using local discontinuities of molecular cues within their environment in vivo, testing purified factors in controlled experiments can provide clues into the mechanism governing axon guidance. In fact, building on Paul's pioneering work, a tremendous number

Correspondence: Timothy M. Gomez, Dept of Neuroscience, University of Wisconsin, 257 Bardeen Labs-SMI, 1300 University Ave., 608-263-4554, 608-262-7306 (FAX), tmgomez@wisc.edu. 
of complex in vitro assays have been developed to examine how environmental factors regulate neurite outgrowth and turning.

As an independent investigator, Paul began working with biologically relevant substrata, such as extracellular matrix (ECM) proteins and cell adhesion molecules. Hammerback and Letourneau first demonstrated that the adhesive properties of ECM proteins could also control the direction of axon extension (Hammarback et al., 1985; Hammarback and Letourneau, 1986; Hammarback et al., 1988). Using electron microscope grids and photolithography to create detailed patterned substrata, neurons were coaxed to adhere and follow specific pathways. Moreover, in support of the guidepost hypothesis (Bentley and Caudy, 1983), Paul's lab showed that growth cones would cross non-adhesive barriers to reach distant islands of adhesive substrata (Hammarback and Letourneau, 1986; O'Connor et al., 1990). These axonal crossings could occur after individual filopodia came in contact with the permissive growth substratum, demonstrating the strong influence filopodia can have on guidance. More recently in collaboration with chemical engineers, Paul's group showed that DRG axons could be guided up an immobilized gradient of a laminin peptide (Adams et al., 2005). The relevance of this work to axon guidance in vivo was supported by tissue labeling experiments showing discrete distributions of ECM proteins along axon pathways in vivo (Rogers et al., 1986).

While conditions in Paul's early experiments indicated that adhesion was a dominant determinant for substratum preference, later experiments suggested that receptor-mediated intracellular signaling may also influence substratum choice. For example, Gomez and Letourneau showed that when given the choice between two growth promoting ECM proteins, laminin (LN) and fibronectin (FN), growth cones often exhibited complex morphological responses upon filopodial contact with the novel substratum (Gomez and Letourneau, 1994). Differences in adhesion alone seemed unlikely to account for such dramatic morphological changes upon limited contact with novel cues. Moreover, while growth cones are more adherent to FN compared to LN, they did not exhibit a clear preference for FN. In fact, many growth cones would avoid FN, while others preferred LN. In addition, using interference reflection microscopy (IRM) to approximate regions of tight membrane to substratum contact, Paul's laboratory found that neurons often failed to extend onto FN despite making many tight filopodial contacts (Gomez et al., 1996). As an offshoot of their IRM imaging, Paul's laboratory was the first to identify growth cone point contacts (Letourneau and Shattuck, 1989; Gomez et al., 1996), which are adhesion sites related to fibroblast focal adhesions. Point contacts are sites of integrin receptor clustering that provide a link to the actin cytoskeleton through a number of adaptor and signaling proteins, including talin, paxillin, vinculin, focal adhesion kinase and Src. This work has been expanded recently to suggest that axon guidance cues regulate the turnover of growth cone point contacts, which is necessary for axon pathfinding in vivo (Robles and Gomez, 2006; Woo et al., 2009).

Work from Paul's laboratory has also provided many insights into the molecular mechanisms governing growth cone adhesion and motility. Several of his early studies examined cell recognition receptors and their ligands. Using proteolytic fragments of FN, Haugen and Letourneau showed that CNS and PNS neurons differed in their ability to extend axons upon heparin-binding versus integrin-binding fragments (Haugen et al., 1992). A role for proteoglycan-mediated and integrin-mediated interactions was confirmed in this study using soluble inhibitors. This and similar studies demonstrated the ECM proteins have multiple binding domains for growth cone receptors with distinct functional outcomes on neuronal morphogenesis. These pioneering studies are relevant to more recent research on matrix metalloproteases, which regulate cell migration and axon outgrowth in vivo (Vaillant et al., 2003; Gonthier et al., 2007; Miller et al., 2008) by degrading ECM proteins and 
possibly by exposing cryptic receptor binding sites. Integrin receptors are particularly important for nerve growth cones, as these receptors localize to both the tips of filopodia where they may serve a sensory function (Letourneau and Shattuck, 1989; Gomez et al., 2001) and within point contacts, where they function in cell adhesion (Letourneau and Shattuck, 1989; Gomez et al., 1996). Condic and Letourneau also showed that the surface expression level of integrin receptors is controlled by a homeostatic process regulated by the density of LN on the substratum (Condic and Letourneau, 1997). At low LN ligand concentration, the amount of cell surface of a $6 \beta 1$ integrin receptors increases. Interestingly, the surface expression level of integrin is controlled by the rate of receptor endocytosis, independent of transcription and translation. By a similar mechanism, sensory neurons were found to adapt to inhibition to aggrecan by both increasing the surface expression and RNA levels of two integrin receptors (Condic et al., 1999).

\section{Neurotrophins as guidance and branching factors}

Growth cone turning in microscopic gradients of chemotropic factors is a highly productive in vitro experimental paradigm that has greatly improved our understanding of the cellular and molecular basis of axon guidance over the last twenty years. Not surprisingly, Paul was one of the first scientists of use this approach to study chemotropism in growth cones. Using soft agar gels, Paul was the first to show that chick DRG neurons would orient up a gradient of NGF (Letourneau, 1978). While NGF was well known as a cell survival factor for DRG neurons, this was the first study to demonstrate that NGF was also a chemoattractant for DRG neurons. Since this time a great number of factors have been found to function both as chemoattractants and chemorepellants using many refined methods to generate gradients (Fan and Raper, 1995; de la Torre et al., 1997; Joanne Wang et al., 2008). Moreover, using growth cone turning as a sensitive readout has allowed researchers to dissect the molecular signaling pathways and cytoskeletal basis for guidance (Song et al., 1997; Lin and Holt, 2008).

Twenty years after his pioneering work with NGF, Paul's lab undertook a resurgent interest in neurotrophin signaling mechanisms with a series of papers by Gallo. However, instead of using neurotrophins as soluble guidance cues, Gallo and Letourneau presented growth cones with a local source of NGF coated onto polystyrene beads (Gallo et al., 1997). The advantage of their approach was that the effects of discrete bead interactions by one or few filopodia could be examined. In their initial report using this approach, they showed that contact of growth cone filopodia with NGF-coated beads resulted in a sharp orientation toward the bead after contact. Turning toward NGF beads was TrkA dependent, but also influenced by low affinity p 75 receptors. Next, it was shown that beads in contact with axonal shafts would promote sprouting of new filopodia and collateral branches (Gallo and Letourneau, 1998). This robust assay allowed a great number of intracellular signaling pathways and cytoskeletal processes to be examined. A number of protein kinases were required for sprouting, but changes in intracellular calcium, a widely accepted first messenger downstream of many guidance factors, was surprisingly not required. As expected, filamentous actin accumulates at sites of bead contact, as well as localized debundling of microtubules. Interestingly, Paul and colleagues have found that Trk and p75 receptors are both required for the effects of neurotrophins on different classes of neurons. In retinal neurons, p75 is necessary for the effects of BDNF on growth cone filopodia (Gehler et al., 2004). Here it appears that unoccupied p75 constitutively activates RhoA to limit filpopodial protrusion and neurotrophins promote filopodial production by inactivating RhoA. Finally, growth cones are believed to be capable of integrating signals from multiple different guidance cues and the effects of one guidance cue may be influenced by the presence of other guidance cues. Consistent with this notion, Paul and colleagues showed 
that neurotrophins could protect DRG neurons from collapse induced by semaphorin3A (Dontchev and Letourneau, 2002).

Paul Letournau's career as a scientist has been dedicated to understanding the inner workings of neuronal growth cones. His dedication has allowed him to contribute greatly to our understanding of how these complex motile machines use environmental factors to guide axons during brain development and regeneration. Importantly, his impassioned fascination with growth cones was an inspiration to the many students and post-doctoral fellows he trained and who now conduct similar studies in their own laboratories.

\section{Acknowledgments}

We thank Kate Kalil and members of the Gomez lab for comments on the manuscript. This work was supported by NIH NS41564.

\section{Bibliography}

Adams DN, Kao EY, Hypolite CL, Distefano MD, Hu WS, Letourneau PC. Growth cones turn and migrate up an immobilized gradient of the laminin IKVAV peptide. J Neurobiol. 2005; 62:134-147. [PubMed: 15452851]

Bentley D, Caudy M. Pioneer axons lose directed growth after selective killing of guidepost cells. Nature. 1983; 304:62-65. [PubMed: 6866090]

Caudy M, Bentley D. Pioneer growth cone morphologies reveal proximal increases in substrate affinity within leg segments of grasshopper embryos. J Neurosci. 1986; 6:364-379. [PubMed: 3950702]

Caudy M, Bentley D. Pioneer growth cone steering along a series of neuronal and non-neuronal cues of different affinities. J Neurosci. 1986; 6:1781-1795. [PubMed: 3712010]

Condic ML, Letourneau PC. Ligand-induced changes in integrin expression regulate neuronal adhesion and neurite outgrowth. Nature. 1997; 389:852-856. [PubMed: 9349817]

Condic ML, Snow DM, Letourneau PC. Embryonic neurons adapt to the inhibitory proteoglycan aggrecan by increasing integrin expression. J Neurosci. 1999; 19:10036-10043. [PubMed: 10559411]

de la Torre JR, Hopker VH, Ming GL, Poo MM, Tessier-Lavigne M, Hemmati-Brivanlou A, Holt CE. Turning of retinal growth cones in a netrin-1 gradient mediated by the netrin receptor DCC. Neuron. 1997; 19:1211-1224. [PubMed: 9427245]

Dontchev VD, Letourneau PC. Nerve growth factor and semaphorin 3A signaling pathways interact in regulating sensory neuronal growth cone motility. J Neurosci. 2002; 22:6659-6669. [PubMed: 12151545]

Fan J, Raper JA. Localized collapsing cues can steer growth cones without inducing their full collapse. Neuron. 1995; 14:263-274. [PubMed: 7857638]

Gallo G, Lefcort FB, Letourneau PC. The trkA receptor mediates growth cone turning toward a localized source of nerve growth factor. J Neurosci. 1997; 17:5445-5454. [PubMed: 9204927]

Gallo G, Letourneau PC. Axon guidance: GTPases help axons reach their targets. Curr Biol. 1998; 8:R80-R82. [PubMed: 9443904]

Gallo G, Letourneau PC. Localized sources of neurotrophins initiate axon collateral sprouting. J Neurosci. 1998; 18:5403-5414. [PubMed: 9651222]

Gehler S, Gallo G, Veien E, Letourneau PC. p75 neurotrophin receptor signaling regulates growth cone filopodial dynamics through modulating RhoA activity. J Neurosci. 2004; 24:4363-4372. [PubMed: 15128850]

Gomez TM, Letourneau PC. Filopodia initiate choices made by sensory neuron growth cones at laminin/fibronectin borders in vitro. J Neurosci. 1994; 14:5959-5972. [PubMed: 7931556]

Gomez TM, Robles E, Poo M, Spitzer NC. Filopodial calcium transients promote substrate-dependent growth cone turning. Science. 2001; 291:1983-1987. [PubMed: 11239161] 
Gomez TM, Roche FK, Letourneau PC. Chick sensory neuronal growth cones distinguish fibronectin from laminin by making substratum contacts that resemble focal contacts. J Neurobiol. 1996; 29:18-34. [PubMed: 8748369]

Gonthier B, Nasarre C, Roth L, Perraut M, Thomasset N, Roussel G, Aunis D, Bagnard D. Functional interaction between matrix metalloproteinase- 3 and semaphoring-3C during cortical axonal growth and guidance. Cereb Cortex. 2007; 17:1712-1721. [PubMed: 17021275]

Hammarback JA, Letourneau PC. Neurite extension across regions of low cell-substratum adhesivity: implications for the guidepost hypothesis of axonal pathfinding. Dev Biol. 1986; 117:655-662. [PubMed: 3758485]

Hammarback JA, McCarthy JB, Palm SL, Furcht LT, Letourneau PC. Growth cone guidance by substrate-bound laminin pathways is correlated with neuron-to-pathway adhesivity. Dev Biol. 1988; 126:29-39. [PubMed: 3342934]

Hammarback JA, Palm SL, Furcht LT, Letourneau PC. Guidance of neurite outgrowth by pathways of substratum-adsorbed laminin. J Neurosci Res. 1985; 13:213-220. [PubMed: 3973933]

Haugen PK, McCarthy JB, Roche KF, Furcht LT, Letourneau PC. Central and peripheral neurite outgrowth differs in preference for heparin-binding versus integrin-binding sequences. J Neurosci. 1992; 12:2034-2042. [PubMed: 1607927]

Joanne Wang C, Li X, Lin B, Shim S, Ming GL, Levchenko A. A microfluidics-based turning assay reveals complex growth cone responses to integrated gradients of substrate-bound ECM molecules and diffusible guidance cues. Lab Chip. 2008; 8:227-237. [PubMed: 18231660]

Lagenaur C, Lemmon V. An L1-like molecule, the 8D9 antigen, is a potent substrate for neurite extension. Proc Natl Acad Sci U S A. 1987; 84:7753-7757. [PubMed: 3478724]

Letourneau PC. Cell-to-substratum adhesion and guidance of axonal elongation. Dev Biol. 1975; 44:92-101. [PubMed: 1132591]

Letourneau PC. Chemotactic response of nerve fiber elongation to nerve growth factor. Dev Biol. 1978; 66:183-196. [PubMed: 751835]

Letourneau PC. Cell-substratum adhesion of neurite growth cones, and its role in neurite elongation. Exp Cell Res. 1979; 124:127-138. [PubMed: 499378]

Letourneau PC. Inhibition of intercellular adhesion by concanavalin A is associated with concanavalin A-mediated redistribution of surface receptors. J Cell Biol. 1979; 80:128-140. [PubMed: 422646]

Letourneau PC, Shattuck TA. Distribution and possible interactions of actin-associated proteins and cell adhesion molecules of nerve growth cones. Development. 1989; 105:505-519. [PubMed: 2612362]

Lin AC, Holt CE. Function and regulation of local axonal translation. Curr Opin Neurobiol. 2008; 18:60-68. [PubMed: 18508259]

Miller CM, Page-McCaw A, Broihier HT. Matrix metalloproteinases promote motor axon fasciculation in the Drosophila embryo. Development. 2008; 135:95-109. [PubMed: 18045838]

O'Connor TP, Duerr JS, Bentley D. Pioneer growth cone steering decisions mediated by single filopodial contacts in situ. J Neurosci. 1990; 10:3935-3946. [PubMed: 2269892]

Robles E, Gomez TM. Focal adhesion kinase signaling at sites of integrin-mediated adhesion controls axon pathfinding. Nat Neurosci. 2006; 9:1274-1283. [PubMed: 16964253]

Rogers SL, Edson KJ, Letourneau PC, McLoon SC. Distribution of laminin in the developing peripheral nervous system of the chick. Dev Biol. 1986; 113:429-435. [PubMed: 3512333]

Rutishauser U. Influences of the neural cell adhesion molecule on axon growth and guidance. J Neurosci Res. 1985; 13:123-131. [PubMed: 3882971]

Schmidt CE, Dai J, Lauffenburger DA, Sheetz MP, Horwitz AF. Integrin-cytoskeletal interactions in neuronal growth cones. J Neurosci. 1995; 15:3400-3407. [PubMed: 7751919]

Song HJ, Ming GL, Poo MM. cAMP-induced switching in turning direction of nerve growth cones. Nature. 1997; 388:275-279. [PubMed: 9230436]

Vaillant C, Meissirel C, Mutin M, Belin MF, Lund LR, Thomasset N. MMP-9 deficiency affects axonal outgrowth, migration, and apoptosis in the developing cerebellum. Mol Cell Neurosci. 2003; 24:395-408. [PubMed: 14572461] 
Woo S, Rowan DJ, Gomez TM. Retinotopic mapping requires focal adhesion kinase-mediated regulation of growth cone adhesion. J Neurosci. 2009; 29:13981-13991. [PubMed: 19890008] 


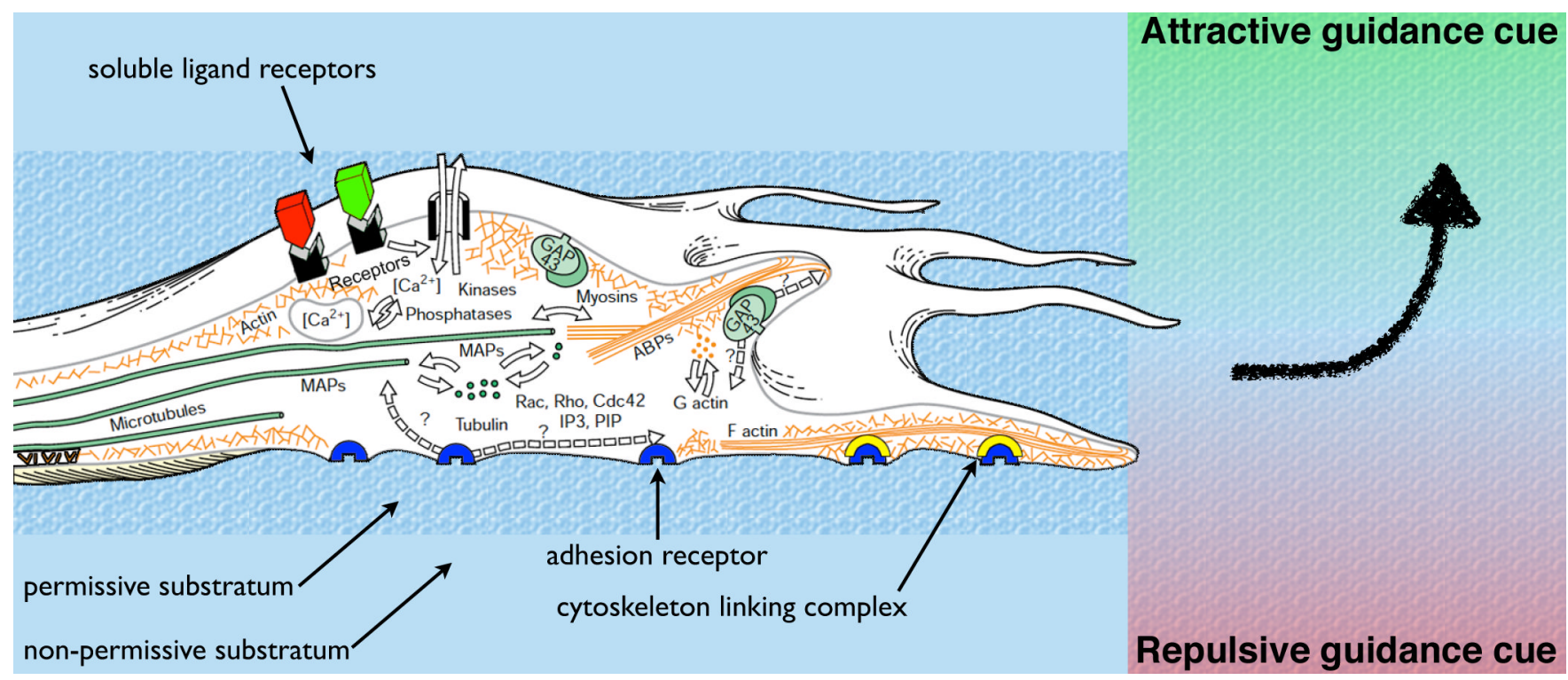

Figure 1.

Schematic model of a growth cone adapted from Gallo and Letourneau (Gallo and Letourneau, 1998), representing important intracellular and extracellular contributors to the regulation of axon pathfinding during development. A permissive substratum is necessary for adhesion of new leading edge protrusions (filopodia and veil), whereas areas that cannot stabilize protrusions do not support outgrowth. Soluble factors that are growth promoting (green) or inhibiting (red) can occur as gradients to guide axon outgrowth along regions that support outgrowth. Substratum associated ligands act on surface receptors that physically link to the actin cytoskeleton through a complex of adaptor proteins. Adhesion receptors and soluble ligand receptors act cooperatively on various intracellular signaling pathways to modulate growth cone motility. Intracellular signals positively or negatively influence motility by regulating the assembly, organization and movements of the cytoskeleton. 